\title{
PRESIDENTE PRUDENTE-SP E A CARÊNCIA DE POLÍTICA HABITACIONAL INCLUSIVA
}

Sibila Corral de Area Leao Honda

Universidade do Oeste Paulista, Curso de Arquitetura e Urbanismo, Presidente Prudente, SP. E-mail: sibila@unoeste.br

\section{RESUMO}

Este artigo visa a contribuir para uma análise crítica sobre a produção da habitação de baixa renda pela iniciativa privada em cidades médias no Brasil, entre os anos 1999 e 2008, verificando seus efeitos no espaço urbano. Aborda o papel dos municípios, pós-Constituição Federal de 1988, com ênfase no Programa de Arrendamento Residencial (PAR), instituído em 1999 pelo Governo Federal; e tem como estudo de caso Presidente Prudente, município localizado no oeste do Estado de São Paulo. Foca a discussão na relação entre as políticas urbanas e habitacionais, assim como na implantação de empreendimentos executados pela iniciativa privada e financiados pela Caixa Econômica Federal, por meio do PAR, e seus mecanismos e efeitos na produção do espaço urbano. Evidencia-se a ausência de diretrizes específicas voltadas para a política habitacional no âmbito da política urbana deste município, induzindo a uma atuação direta do capital privado, que contribui para a produção de espaços urbanos segregados e excludentes.

Palavras - chave: Política Urbana, Expansão Urbana, Segregação Socioespacial, Habitação de Interesse Social, Programa de Arrendamento Residencial.

\section{PRESIDENTE PRUDENTE -SP AND THE DEFICIENCY OF INCLUSIVE HOUSING POLICY}

\begin{abstract}
This paper intents to contribute to a critical analysis on the production of low-income housing by the private sector in medium-sized cities in Brazil, between 1999 and 2008, examining their effects on urban space. Discusses the role of municipalities, post-1988 Brazilian Federal Constitution, with emphasis on the Programa de Arrendamento Residencial (PAR), established in 1999 by the Federal Government, and taking as a case study Presidente Prudente, a city located west of Sao Paulo State. Its focus is to discuss the relationship between the urban and housing policies and enterprises implementation by the private initiative and funded by the Caixa Economica Federal, through the PAR, its mechanisms and effects on the production of urban space. It is evident in the urban policy of this city that the absence of specific guidelines towards housing policy leads to a direct action of private capital, which contributes to the production of urban segregation and exclusion.
\end{abstract}

Keywords: Urban Policy, Urban Expansion, Sociospatial Segregation, Social Interest Housing, Programa de Arrendamento Residencial. 
INTRODUÇÃO

Este artigo tem como foco a compreensão sobre a recente produção da habitação de baixa renda no espaço urbano de cidades de porte médio. Com base no estudo de caso de Presidente Prudente, cidade média do interior do Estado de São Paulo, discute-se a produção da habitação social por agentes privados, por meio do Programa de Arrendamento Residencial (PAR) da Caixa Econômica Federal.

Num contexto de intenso processo de urbanização, ocorrido principalmente a partir da década de 1960 no Brasil, inúmeros são os desafios relativos às políticas públicas e à gestão e organização do território municipal. A urbanização elevou ao mesmo tempo a demanda por moradia num quadro de precariedade, que inicialmente é visível nos grandes centros urbanos, mas que tem se propagado rapidamente para as cidades nãometropolitanas (FELDMAN, 2003).

Parte-se do pressuposto que 0 enfrentamento dos graves problemas que atingem as cidades brasileiras requer soluções articuladas de planejamento e gestão urbanos. Nesse contexto, a formulação de políticas públicas adequadas, particularmente àquelas relativas ao uso do solo urbano, à habitação, à infraestrutura de saneamento básico e de transportes, ao meio ambiente, etc., deve contribuir para a construção de ambientes urbanos equilibrados e justos.

$$
\text { Principalmente a partir da }
$$

Constituição Federal de 1988 as temáticas da política urbana e da gestão das cidades, no Brasil, passaram a ocupar um lugar de destaque em diversas esferas institucionais, políticas e sociais. A promulgação da Constituição teve como base o fortalecimento do Município, com sua autonomia política, administrativa e financeira ampliada.

$\mathrm{Na}$ esfera das políticas urbanas, a questão da política habitacional passou a ser central e estratégica para os Municípios, uma vez que um dos principais problemas é a provisão de moradias adequadas à grande parcela da população; apesar da competência nessa área ser das três esferas de Governo: Federal, Estadual e Municipal. Embora o Município não tenha competência isolada sobre a política habitacional, a responsabilidade de implementação de uma política urbana justa e equitativa, com objetivos de justiça social e de qualidade de vida, prevista no Estatuto da Cidade (Lei Federal $\left.n^{\circ} .10 .257 / 2001\right)$, inclui estratégias de elaboração de políticas públicas setoriais, principalmente a da habitação, na escala local.

Durante a década de 1990, um conjunto de crises políticas e institucionais no 
âmbito da política federal fez com que as áreas da habitação e do desenvolvimento urbano permanecessem sem contar com recursos financeiros expressivos e sem capacidade institucional de gestão. (Ministério das Cidades, 2004),

Ao ampliar as condições de autonomia e de iniciativa locais na definição de agendas e implementação de políticas públicas, as iniciativas em programas habitacionais, por parte de administrações municipais, disseminaram-se a partir do final dos anos de 1980, e ganharam maior legitimidade durante os anos de 1990 e inicio dos anos 2000, na medida em que foram também apoiadas pelas novas políticas de financiamento em curso no Brasil. Nesse contexto, surgiram novas linhas de financiamento habitacional promovidas pelo Governo Federal, a partir da Caixa Econômica Federal, que visavam a beneficiar os Governos Estaduais e Municipais, apoiadas na iniciativa privada.

A partir da década de 1990, ocorre a entrada de uma fatia da iniciativa privada na produção de unidades habitacionais, para o mercado de baixa renda, por meio de vários programas governamentais, entre eles 0 Programa de Arrendamento Residencial (PAR), que passou a se constituir em uma oportunidade para o Governo Municipal resolver parcelas significativas de seus problemas relacionados à demanda crescente por habitação.

No entanto, para além da possibilidade de contribuição com a construção de novas moradias para a baixa renda pelo setor privado, destaca-se o papel do Município como gestor municipal, sendo fundamental que este regule a atuação do mercado imobiliário na produção de moradias de baixa renda, em consonância com a política de desenvolvimento urbano e com as diretrizes que vão ao encontro dos propósitos da função social da cidade.

Paralelamente, como parte do processo de planejamento urbano, atualmente os Municípios brasileiros vêm incorporando os instrumentos urbanísticos fundamentais à questão, e, entre eles a Zona Especial de Interesse Social - ZEIS (artigo 4응 da Lei no.10.257/2001), área a ser delimitada pelo Poder Público Municipal, no Plano Diretor, destinada à implantação de habitação de interesse social. Entretanto, tal possibilidade não necessariamente vem sendo traduzida da mesma maneira por todos os municípios brasileiros, por motivos diversos, seja pela sua condição financeira, pela incapacidade político institucional, ou mesmo, pelo continuo descaso em relação às questões urbana e habitacional.

No caso do Município de Presidente Prudente, a ausência histórica de políticas públicas inclusivas - urbanas e habitacionais 
- contribuiu para que a produção do espaço urbano ocorresse segundo os interesses do capital, resultando em uma mancha urbana dispersa e fragmentada composta de espaços altamente segregados e excludentes.

Embora o Município tenha atendido à orientação legal da política urbana federal em relação à instituição de um Plano Diretor voltado a direcionar o seu desenvolvimento urbano, a parti da Constituição Federal de 1988, evidencia-se um desinteresse de ação, de regulação legal e de estímulo à redução da segregação no espaço urbano pelo Poder Público Municipal, particularmente na definição de áreas voltadas para a implementação de habitação de interesse social.

A lacuna em relação à habitação social em Presidente Prudente-SP, representada pela carência de investimentos públicos e pela alta taxa de população com alta vulnerabilidade social $^{1}$, gera grande necessidade de investimentos na construção e financiamento de moradias para população de renda baixa.

Para atender à crescente demanda por habitação da baixa renda, em 2001, Presidente Prudente foi um dos Municípios beneficiados no Estado de São Paulo pelo

\footnotetext{
${ }^{1}$ Segundo a Fundação Seade, em 2000, 24,6\% do total da população do Município de Presidente Prudente apresentava alta vulnerabilidade social, acima da média do Estado de São Paulo, que era de $17,6 \%$.
}

Programa de Arrendamento Residencial (PAR), criado em 1999 pelo Governo Federal.

Entre 2003 e 2006 foram executados cinco empreendimentos com características distintas; e com os dois patamares de renda estipulados pelo programa: PAR 1 (para renda de até seis salários mínimos) e PAR 2 (para renda de até três salários mínimos).

No âmbito deste contexto, o artigo procura discutir a produção da habitação de baixa renda na cidade de Presidente Prudente, promovida por agentes privados no âmbito do Programa de Arrendamento Residencial (PAR) da Caixa Econômica Federal e os seus efeitos na produção social do espaço urbano.

Busca-se verificar se a recente produção de habitação tem considerado os novos aspectos políticos e legais, a partir da Constituição Federal de 1988, assim como a incorporação dos instrumentos urbanísticos no âmbito municipal, ou se continua reproduzindo a localização e as estratégias de implantação de habitação social historicamente identificadas no país.

\section{PRODUÇÃO DO ESPAÇO URBANO E POLÍTICAS PÚBLICAS: EFEITOS E AGENTES}

Caracterizando o conceito de política pública, Monteiro (1982, p.12), afirma que é "ação (ou inação) conscientemente escolhida e orientada para um determinado fim". Cunha e Cunha (2002) focam na coletividade 
e nas demandas da sociedade, concretizando os direitos sociais (Direito Coletivo) e sua legitimidade; embora esclareçam que, apesar dessa legitimidade na criação das políticas públicas pelo Estado, "elas englobam preferências, escolhas e decisões privadas, podendo (e devendo) ser controladas pelos cidadãos" (Cunha e Cunha, 2002, p.12).

A atenção a diferenças no contexto das políticas públicas é fundamental na análise do objeto políticas urbanas, tanto conceitualmente quanto no estudo das ações e seus resultados. Em relação a estes, é crucial a constante adequação da gestão das políticas, pois podem ser observados direcionamentos imprevisíveis, cujos rumos impõem reformulações. Mas, atentando para Villaça (1999, p.180), as políticas urbanas "devem referir-se às reais ações e às propostas consequentes de ação do Estado sobre o urbano".

As políticas urbanas implicam uma dimensão de natureza real, da ação. No exercício da sua vontade é necessária a análise dos atores e das regras da ação política. Entretanto, as decisões não são justas a todos, havendo grande diversidade de interesses, e o discurso não reflete necessariamente a realidade da ação, e muitas vezes, há uma imposição legal no espaço urbano, criando, reproduzindo ou reforçando características de expansão e/ou segregação urbanas (Lacaze, 1999).
Segundo Alvim, Castro e Zioni (2010, p.13), as políticas urbanas podem ser identificadas como políticas públicas voltadas às demandas e práticas sociais locais; e afirmam que são várias as áreas passíveis de atuação do Poder Público no âmbito local, sendo a política habitacional considerada uma política urbana especifica, setorial. No entanto, mesmo sendo parte da política urbana, a política habitacional pode envolver programas de responsabilidade de qualquer um dos três níveis de Governo: Federal, Estadual e Municipal.

Rolnik et al (2004, p.73) afirmam que a "política habitacional é instrumento para alcançar o direito à moradia e passa, necessariamente, pela esfera municipal". Esses autores informam que essa política apresenta importância significativa na gestão e no desenvolvimento urbanos, refletindo nos aspectos de produção social do espaço urbano, como territorial, pela expansão, reprodução e adensamento; social, com segregação; e econômico. Assim sendo, seu direcionamento deve ser dado com foco na sociedade à que se aplica, na satisfação de suas necessidades e na sua capacidade (econômica e de reprodução).

Para alcançar o propósito de cada política urbana, faz-se necessário que as dimensões política e técnico-científica estejam alinhadas, revendo e reordenando os instrumentos de planejamento e gestão, com 
atenção a questões de valor e objetivos. Como também é fundamental a participação popular, inclusive quando em disputas de grupos de interesses; sendo importante verificar quais os agentes e suas reais forças na construção da realidade.

Conforme Valladares (1983), a produção do espaço urbano pode ser vista por meio da ação de um conjunto de agentes: o proprietário fundiário, o loteador, o corretor imobiliário, o Estado e o morador. Marques (2005, p.216) informa que em um limite do processo constam os agentes envolvidos com a comercialização no mercado imobiliário urbano, e no outro extremo, encontram-se os proprietários fundiários; e em posições intermediárias, encontram-se os construtores e os incorporadores, sendo que estes articulam os demais, uma vez que definem o produto imobiliário a ser lançado e sua localização.

A produção do espaço urbano capitalista conforme afirma Corrêa (1999) é fragmentado, reflexo e condicionante social, com jogos de interesse, articulados por agentes que produzem e consomem espaço, sendo que a atuação do Estado visa a criar condições para os processos de acumulação e de reprodução das classes sociais, por meio de mecanismos que levam à segregação socioespacial.

Nas análises e discussões sobre segregação espacial elaboradas por Villaça
(1998), o autor deixa bastante explícito que esse processo é dialético, no qual a segregação de uns provoca a segregação de outros, imediatamente, e que o processo de dominação - econômica, política e social necessita da segregação como forma de controle.

A segregação socioespacial é uma característica bastante relevante nas cidades, segundo Caldeira (2003), pois as normas e legislações que organizam o espaço urbano estão baseadas em padrões de diferenciação e de separação.

Para Santos (2005), o poder público também estimula a especulação e a existência de vazios urbanos, pois, incapaz de resolver o problema da habitação, ele empurra a população com menos recursos para as periferias; e, dessa forma, age direta e indiretamente na geração de problemas urbanos, mas com discurso ideológico diferente.

O processo de produção do espaço urbano no município de Presidente Prudente revela a existência de grande segregação socioespacial principalmente quando se analisa a sua estrutura urbana e a distribuição dos conjuntos habitacionais de baixa renda produzidos, desde a década de 1960, por agentes públicos e privados, como se pode ver a seguir. 
O PROCESSO DE PRODUÇÃO DO ESPAÇO URBANO EM PRESIDENTE PRUDENTE E A HABITAÇÃO DE BAIXA RENDA

Presidente Prudente localizada no oeste paulista, na região conhecida como Alta Sorocabana, teve sua base de colonização apoiada na produção agropecuária e na implantação da estação ferroviária no início do século XX (inaugurada em janeiro de 1919).

A definição de sua estrutura urbana relacionou-se diretamente com a abertura de dois loteamentos: Vila Goulart e Vila Marcondes, sendo o primeiro aberto junto à estação ferroviária que estava em construção, em 1917; e o segundo aberto em 1919, como suporte ao comércio de terras rurais, situando-se do lado oposto da linha férrea.

Ainda nos primeiros anos, a Vila Goulart assumiu o papel de centro comercial e área residencial das famílias mais abastadas, enquanto a Vila Marcondes passou a atrair as empresas de beneficiamento agrícola ao longo da linha ferroviária e bairro residencial das classes mais baixas. A cidade, assim como sua região, dependia diretamente da produção agrícola (Honda, 2000).

Em 1921, o município de Presidente Prudente foi criado legalmente, como centro político e administrativo regional. A produção cafeeira foi a base econômica da região até início da década de 1930, quando se observa a entrada do algodão na produção agrícola, e intensifica-se a pecuária de corte. A cidade assumiu papel de base comercial, de prestação de serviços e de beneficiamento da produção agrícola para a Alta Sorocabana.

A expansão urbana em Presidente Prudente sempre ocorreu de forma mais dinâmica na direção sudoeste, como prolongamento da Vila Goulart. Entre a década de 1920 e primeira metade da de 1950, a cidade apresentou significativa expansão territorial, sem planejamento e sem regularização legal. A informalidade na organização fundiária do território prudentino foi a prática, atingindo diretamente a produção da cidade, com grande expansão da malha urbana (Honda, 2000).

A estrutura política da cidade se formou baseada no coronelismo, apoiada inicialmente nas figuras dos 'Coronéis' Goulart e Marcondes, reproduzida ao longo dos anos. Abreu (1996) afirma que a 'Revolução de 1930' não alterou as práticas políticas prudentinas, sendo que do coronelismo passou-se para o populismo.

A partir da mudança do sistema de governo em 1964, Spósito (1990) afirma que ocorreu certa moralização, motivada pela possibilidade de ampliação da arrecadação municipal, pelo Poder Público, tendo 
provocado regularização de loteamentos e lotes.

Em 1968, o Centro de Pesquisas e Estudos Urbanísticos (CPEU), da Faculdade de Arquitetura e Urbanismo da Universidade de São Paulo (FAU-USP), elaborou o primeiro Plano Diretor para a cidade. Também nesse ano, o Município foi beneficiado com a construção do primeiro conjunto habitacional, com financiamento do $\mathrm{BNH}, \mathrm{O}$ Parque Continental, localizado na franja urbana da cidade, formado por 142 casas unifamiliares. Importante observar que o loteamento onde foi implantado esse empreendimento estava aberto desde 1962, em área bastante isolada na região sul da cidade.

Durante as décadas de 1970 e 1980, a cidade apresentou grande expansão territorial urbana; mas sem acompanhamento do crescimento demográfico urbano (Sposito, 1983). A expansão urbana pode ser mais sentida na direção sudoeste, criando grandes vazios no traçado da cidade, por longos períodos de tempo. A malha urbana praticamente dobrou nesse período.

A partir da década de 1970 começa a se configurar um espaço urbano altamente segregado na cidade, segundo Marisco (2003), com participação direta de vários agentes - Poder Público local, incorporadores imobiliários e proprietários fundiários - que agiram no direcionamento da expansão urbana, assim como na destinação das áreas e regiões voltadas às populações de alta e baixa rendas. Entre os anos de 1975 e 1977, ocorreu grande elevação dos preços dos terrenos, com ampliação do processo de implantação de loteamentos na cidade.

Entre 1973 e 1981, a cidade apresentou uma realidade extremamente favorável à reprodução do capital. No entanto, muitos loteamentos abertos na cidade somente receberam moradores após serem utilizados para construção conjuntos habitacionais. O aumento de impostos e o processo de implantação de conjuntos habitacionais na franja urbana do Município incentivaram o deslocamento da população de menor renda, com redução da ocupação urbana das áreas mais centrais da cidade, reforçando ainda mais a segregação socioespacial. A maior parte dos conjuntos habitacionais, entre os anos de 1976 e 1980, foi implantada na região oeste da cidade (Honda, 2011).

Importante ressaltar que, embora muitos desses empreendimentos foram implantados para além da malha urbana, em loteamentos previamente aprovados e abertos na cidade, eles serviram para estimular a incorporação privada em novas áreas da periferia urbana, principalmente a oeste e norte da cidade; incentivando o processo de segregação espacial. 
A partir de 1983, com um novo Governo Municipal ${ }^{2}$, e tendo cessado o fluxo de financiamento externo no Brasil, resultando em crise nacional, ocorreu uma mudança no percurso histórico de oferta de lotes e loteamentos no município, com poucos investimentos públicos em habitação social e privados em terra (Torrezan, 1992).

Segundo Spósito (1990), o ano de 1988 sinaliza uma transformação na política habitacional municipal, apresentando no discurso a busca pela resolução do problema habitacional, inclusive com utilização da desapropriação ou por meio de parcerias com empresas privadas para construção de moradias. A nova Constituição Federal foi sancionada nesse ano, com inclusão de capítulo específico sobre política urbana e exigência de Plano Diretor municipal.

A Companhia de Desenvolvimento Habitacional e Urbano (CDHU), da Secretaria de Habitação do Estado de São Paulo, criada em 1989, aprovou e financiou, entre 1990 e 1997, um total de 1.782 unidades residenciais em Presidente Prudente (Fernandes, 1998). E, durante os anos de 1990 e 1993, 2.757 unidades habitacionais foram construídas e entregues por meio de financiamento do Programa de Ação Imediata de Habitação (PAIH), do Governo Federal.

\footnotetext{
${ }^{2}$ Foi eleito para Prefeito Municipal o Sr. Virgílio Tiezzi Júnior, na primeira eleição municipal ocorrida a partir do processo de redemocratização no país.
}

$\mathrm{Na}$ gestão municipal compreendida entre 1993 e 1996, houve concessão de Direito Real de Uso de 4.013 lotes urbanizados no município, sem participação de Governo Federal ou Estadual, mas todos em glebas localizadas além da malha urbana, nas regiões norte e noroeste. No último ano desse Governo Municipal, foi aprovado o novo Plano Diretor para a cidade por meio da Lei Municipal no.29/1996.

Durante a presidência de Fernando Henrique Cardoso (1995-2002), a Política Nacional de Habitação visava à descentralização da execução dos programas habitacionais, com incentivo a ações dos Governos Municipais como agentes promotores de habitação social. Paralelamente, durante a gestão municipal compreendida no período de 1997 a 2000, cinco empreendimentos de habitação social foram executados na cidade, sendo que nenhum teve financiamento do Governo Federal.

Em 1999, foi editada a Medida Provisória nº.1.823/99, que criou o Programa de Arrendamento Residencial (PAR), pelo Governo Federal, como nova forma de agenciamento da habitação. Esse programa veio a beneficiar Presidente Prudente com a construção de habitações para a população de baixa renda entre os anos de 2003 e 2006. Concomitantemente, em Janeiro de 2008 , foi 
aprovada a revisão do Plano Diretor (Lei Municipal n‥151/2008).

Ao longo do processo de produção do espaço urbano de Presidente Prudente evidencia-se que a estruturação da cidade permanece com áreas segregadas, o setor sudoeste atrai os loteamentos e os condomínios de alta renda; a oeste e a norte localizam-se as camadas de menor poder aquisitivo.

O processo de expansão da malha urbana ocorre com manutenção de grandes vazios urbanos, muito embora o Município, entre 1996 e 2008, tenha instituído dois Planos Diretores que incorporaram parte dos princípios constantes na Constituição Federal e no Estatuto da Cidade.

\section{POLÍTICA URBANA EM PRESIDENTE} PRUDENTE: PLANOS DIRETORES PÓS 1988 E A QUESTÃO DA HABITAÇÃO

O processo de expansão urbana ocorrido em Presidente Prudente até o final da década de 1960 não teve regulação urbanística ou normatização legal, podendo ser verificados vários períodos de ampliação da malha e do perímetro urbano.

Em 1968, o município foi objeto do primeiro Plano Diretor, denominado Plano Diretor de Desenvolvimento Integrado (PDDI), com metodologia especificada pelo Serviço Federal de Habitação e Urbanismo (SERFHAU), desenvolvido pelo CPEU da
FAUUSP. Marisco (1997) ressalta que o PDDI visava a políticas e diretrizes para todo o município de Presidente Prudente, mas que não foram implantadas. Como decorrência do PPDI, foi instituído o primeiro zoneamento urbano (Lei $\left.\mathrm{n}^{\circ} .1 .583 / 1973\right)$. O PDDI e o zoneamento urbano ficaram em vigor até o ano de 1996.

No ano de 1990, foi aprovada a Lei Orgânica do município de Presidente Prudente. Com base nessa lei, e decorrente da obrigatoriedade definida pelas Constituições Federal (1988) e Estadual (1989); em 1996, foi elaborado e aprovado o novo Plano Diretor municipal (PD), como Lei Municipal $n^{\circ} .29 / 1996$.

Entre as políticas setoriais definidas, na seção sobre a política habitacional constam diretrizes gerais de ação pública, que, no entanto, não foi objeto de detalhamento e nem posteriormente de legislação especifica.

Do conjunto dos instrumentos previstos no PD, foram previstos o zoneamento, o parcelamento ou edificação compulsórios, o IPTU progressivo no tempo, e as Zonas Especiais de Interesse Social (ZEIS). No entanto, somente o zoneamento foi alvo de legislação específica, a Lei Complementar Municipal $n^{\circ} .31 / 1996$, que instituiu o Zoneamento de Uso e Ocupação do Solo Urbano. Os demais não foram objetos de detalhamento e nem sequer as 
áreas ou regiões prioritárias passíveis de aplicação desses instrumentos foram definidas.

Em 1998, foi aprovada a primeira lei municipal que trata de Zonas Especiais de Interesse Social - ZEIS (Lei Complementar Municipal $\left.n^{\circ} .53 / 1998\right)$, que não chegou a definir as áreas passíveis de aplicação do instrumento. Esta lei possibilitou ao proprietário imobiliário interessado o poder de requerer junto à Prefeitura a alteração do zoneamento de sua área para ZEIS.

No ano de 2001, foi sancionada a Lei Federal no.10.257/2001 (Estatuto da Cidade), que regulamenta os artigos 182 e 183 ("Da Política Urbana") da Constituição Federal. Apesar das maiores possibilidades de aplicação de instrumentos urbanísticos para controle, planejamento e gestão das cidades, a cidade de Presidente Prudente não assumiu imediatamente a posição de revisão do Plano Diretor. Porém, na contramão do discurso, em 2003, institui uma nova Lei de Zoneamento de Uso e Ocupação do Solo Urbano (Lei Complementar $\mathrm{n}^{\circ} .128 / 2003$ ), com inclusão de dois outros instrumentos urbanísticos, embora não definidos no Plano Diretor que deveria ter sido revisado: o Estudo de Impacto de Vizinhança (EIV) e a Outorga Onerosa do Direito de Construir.

Em 2005 foi divulgada a Resolução $\mathrm{n}^{\circ} .34$ do Conselho Nacional das Cidades, que estabeleceu que os Planos Diretores municipais deveriam incluir os objetivos, temas prioritários e estratégias de desenvolvimento e reorganização territorial municipais, entre outros aspectos.

Somente em 2007 é que ocorreu o processo de discussão e revisão do Plano Diretor, tendo sido aprovado no início de 2008, por meio da Lei Municipal n.151/2008. No entanto, esse novo Plano não considera a resolução acima citada, não apresentando objetivos, diretrizes ou estratégias de desenvolvimento, e mais uma vez não identifica áreas passíveis de aplicação dos instrumentos urbanísticos aprovados.

No novo Plano Diretor, a política habitacional basicamente repete os artigos do PD anterior, e, da mesma maneira, não faz menção a ZEIS, deixando que esse assunto fosse tratado apenas na Lei Complementar Municipal $n^{\circ} .153 / 2008$, que dispõe sobre o novo Zoneamento de Uso e Ocupação do Solo Urbano. Esta lei, por sua vez, também não define as áreas que deveriam ser alvos de ZEIS, mantendo a indicação que o proprietário poderá solicitar a alteração do zoneamento transformando as suas terras em ZEIS, de acordo com seus interesses particulares. Ou seja, a função social da propriedade é claramente descartada.

Embora esse novo PD tenha incorporado alguns instrumentos urbanísticos, observa-se que a maioria destes instrumentos sequer foi regulamentado, 
ficando a produção do espaço urbano à mercê do mercado privado de terras.

A implantação de habitação social na cidade de Presidente Prudente tem-se mostrado dependente das ações públicas federais e estaduais, e privadas. Conjuntos habitacionais têm sido construídos no município sem direcionamento do poder local sobre áreas prioritárias, ou mesmo buscando diminuir vazios urbanos ou áreas subutilizadas, que contribuiriam assim para reduzir a segregação socioespacial (Honda, 2011).

No âmbito do Programa de Arrendamento Residencial (PAR), cujo convênio entre a CAIXA e a Prefeitura Municipal foi assinado em 2001, nos anos de 2003 a 2006 foram construídos cinco empreendimentos que serão analisados a seguir. Buscou-se verificar a participação efetiva do Poder Público e os efeitos sobre a produção do espaço urbano prudentino.

\section{O PROGRAMA DE ARRENDAMENTO} RESIDENCIAL (PAR) EM PRESIDENTE PRUDENTE

Em 1998, ocorreu a reeleição do então Presidente da República, Fernando Henrique Cardoso, para o quadriênio 19992002. A Política Nacional de Habitação (PNH), em vigor à época, apresentava entre os aspectos básicos, a descentralização da execução de programas de habitação, saneamento e infraestrutura; atentando às diferenças regionais da sociedade e suas demandas. No âmbito dos programas de financiamento da política habitacional, destaca-se o Programa de Arrendamento Residencial (PAR), instituído pela Medida Provisória $\mathrm{n}^{\circ} .1 .823 / 1999$, transformada na Lei $n^{\circ} .10 .188 / 2001$.

O PAR foi criado como resposta ao não atendimento da população de menor renda (até seis salários mínimos) no financiamento de habitação nos demais programas implementados até então. Além disso, havia a constatação de que $65 \%$ dos ocupantes dos imóveis financiados para baixa renda pela Caixa Econômica Federal não estavam mais nas mãos dos adquirentes originais (Caixa Econômica Federal, 2008), fato que levava a ser repensado o modelo de aquisição com dinheiro público da habitação de baixa renda. A principal diferença do PAR consistia na não aquisição direta do imóvel, por meio da figura do arrendamento, em que o arrendatário tem a opção de compra depois de transcorrido tempo de residência no imóvel.

A definição de prioridades para implantação do programa deveria ser feita pelo Poder Público municipal, baseado no Plano Diretor aprovado, segundo as áreas caracterizadas como prioritárias ou zonas de interesse social (ZEIS), por meio de estudos de expansão urbana e déficit habitacional; ou 
seja, a relação com a política urbana local era essencial.

Bonates (2008) afirma que, a partir de 2003, com o Governo do Presidente Luis Inácio Lula da Silva, alterações legais no programa ocorreram, que modificou o perfil de produção do PAR: de conjuntos residenciais localizados na malha urbana, para conjuntos localizados fora da malha urbana, podendo ser verificada tendência para maior atendimento à população de renda mais baixa, em função da aquisição de terras mais baratas pela iniciativa privada.

Essa característica possibilitou o retorno da implantação de empreendimentos de habitação social nas áreas periféricas, com menor inclusão da população beneficiada aos serviços e infraestruturas urbanas.

Em Presidente Prudente, os cinco empreendimentos executados com financiamento do PAR foram implantados em locais definidos pelo capital imobiliário, em geral nos limites da franja urbana, ou em bairros afastados do centro da cidade.

Como já destacado, nessa cidade, as zonas especiais para habitação de interesse social são definidas de acordo com o interesse do proprietário de terras urbanas que tem liberdade para solicitar a alteração do zoneamento para ZEIS. Dessa forma, proprietários visando a repassar suas áreas para construção de habitação social pelos Governos Federal ou Estadual, têm liberdade de solicitar a alteração do zoneamento de suas glebas, como tem ocorrido com as áreas onde são implantados os conjuntos financiados pela CDHU na cidade.

Assim, a Prefeitura não se envolveu na definição de áreas ou regiões prioritárias, como também não indicou, com informação atualizada, o déficit habitacional por regiões da cidade. A própria candidatura da cidade ao Programa foi iniciativa de agentes privados locais (imobiliárias e proprietários de terras), interessados em investir no mercado de habitação social.

As políticas urbana e habitacionais municipais em Presidente Prudente têm se mostrado bastante vagas e permissivas, possibilitando ações diretas especulativas e segregadoras no espaço urbano.

A distribuição espacial dos empreendimentos na malha urbana foi baseada na oferta de áreas privadas, sem relação com déficit habitacional setorizado, disponibilidade de serviços e/ou equipamentos urbanos, ou outro levantamento elaborado. A definição do patamar de renda alcançada, definindo a categoria do PAR (se PAR 1, para renda de até 6 salários, ou PAR 2, para renda de até 4 salários), apoiou-se exclusivamente na disponibilidade de verba do banco financiador (CAIXA); ou seja, no limite de verba liberada para a Gerência de Desenvolvimento Urbano da CAIXA (GIDUR) 
de Presidente Prudente para financiamento em cada patamar do PAR.

A Prefeitura Municipal de Presidente Prudente, nos processos do PAR, participou apenas na aprovação dos projetos junto à Secretaria de Planejamento, e colaborou com parte dos cadastramentos de interessados.

Os conjuntos habitacionais executados diferem-se quanto à tipologia construtiva, área de implantação, quantidade de famílias beneficiadas, valores de financiamento, e relação com a estrutura urbana. Mas a reprodução das características de implantação da habitação social em áreas distantes na malha urbana foi mantida nos conjuntos do PAR.

Analisando os cinco empreendimentos do PAR, além da questão da implantação periférica, verifica-se que, apesar das localizações diferirem entre si, estes se situam em áreas de concentração de população de menor poder aquisitivo, incluindo áreas na zona leste (Laura), zona norte (Atalaia), zona sul (Esmeralda e Monte Carlo) e região noroeste (Bela Vista). Essas localizações reforçam o processo de segregação socioespacial na produção do espaço urbano da cidade, já deflagrado em anos anteriores.

Entre os empreendimentos do PAR, quatro se localizam na franja urbana, havendo grande distância ao centro urbano, acessibilidade reduzida, e contribuem para a expansão e a fragmentação urbanas. O quinto empreendimento se situa em vazio urbano, na região norte da malha, junto à Secretaria Municipal de Obras e próximo a loteamentos de interesse social.

$$
\text { Aliado a estes novos }
$$
empreendimentos, observa-se a manutenção dos grandes vazios urbanos entre a área central e as periféricas, reforçando a valorização imobiliária destes terrenos, frutos de especulação, bem como a segregação socioespacial urbana.

Dos conjuntos analisados, quatro empreendimentos são condomínios fechados, cujo modelo induz ao isolamento da vizinhança imediata, reproduzindo valores relacionados à segurança e status tal qual nos condomínios de alta renda. Observa-se que nos casos analisados, o marketing que associa condomínio à segurança também tem atingido as camadas mais pobres da sociedade, reproduzindo os "enclaves fortificados" tão discutido por Caldeira (2003), ainda que em menor escala. O desinteresse da administração pública em restringir a aprovação desses 'enclaves' urbanos propicia sua reprodução.

Nos processos de aprovação desses conjuntos junto à Secretaria de Planejamento da Prefeitura Municipal de Presidente Prudente, não foram consideradas as zonas vigentes, devendo, exclusivamente as construtoras proponentes, a adequação por 
meio da aquisição da área para projeto, assim como a análise dos índices dessas zonas. Segundo a Lei de Uso e Ocupação do Solo então vigente (Lei Complementar $\left.n^{\circ} .128 / 2003\right)$, apenas os conjuntos residenciais Bela Vista, Esmeralda e Monte Carlo foram implantados em zona de uso permitido. À época de aprovação desses empreendimentos era proibida a aprovação e execução de empreendimento de habitação de interesse social em ZR1, local de implantação do Conjunto Residencial Atalaia. Nesse caso, com o agravante de ser conjunto vertical em área de ocupação horizontal de baixa densidade. O Conjunto Residencial Laura apresenta onze edifícios com quatro pavimentos cada, e foi implantado em zona de ocupação de até 2 pavimentos, excedendo a ocupação permitida.

Apesar da busca por rápida aprovação de empreendimento considerado de habitação social, sendo verificada sua necessidade no Município, não estavam definidas no Plano Diretor ou no Zoneamento vigentes as áreas voltadas ao interesse social; cabendo ao proprietário de terras urbanas a solicitação de alteração de zoneamento para aquela finalidade, fato concretizado.

Ainda hoje, em relação à definição legal de áreas para habitação social, especificamente as ZEIS, a Prefeitura não tem intenção de sua delimitação, segundo entrevista realizada com os funcionários da
Secretaria de Planejamento, Desenvolvimento Urbano e Habitação Municipal, pois considera que haveria diminuição da oferta de moradia popular pela iniciativa privada e restrição à pouca capacidade de ação do Poder Público municipal.

A Prefeitura Municipal de Presidente Prudente não teve participação direta na definição dos empreendimentos financiados pelo PAR, na cidade; não auxiliou na definição de áreas, uma vez que não a possuía análise urbana para embasar diretrizes de escolha; e muito menos articular a definição das áreas de demandas ao déficit habitacional. Sua ação foi passiva nos processos analisados.

Durante a execução da pesquisa em questão, constatou-se também que a Prefeitura Municipal não possui controle dos empreendimentos aprovados financiados pelo Programa de Arrendamento Residencial, nem das famílias beneficiadas.

Por fim, a análise dos cinco casos de Conjuntos Habitacionais financiados pelo PAR, em Presidente Prudente, possibilitou verificar a falta de controle sobre a oferta e a demanda de habitação na cidade, resultando em uma produção segregada e excludente do espaço urbano, dirigida pelo capital privado. 


\section{CONSIDERAÇÕES FINAIS}

Por meio da análise dos Planos Diretores aprovados no município e da legislação complementar, pode-se verificar que a política urbana implementada em Presidente Prudente deixa lacuna quando trata dos instrumentos urbanísticos e das políticas setoriais, principalmente da política habitacional. O município carece de uma política urbana inclusiva, em prol de uma cidade menos segregada, com utilização de instrumentos que sejam utilizados na tentativa de diminuir a especulação imobiliária e possibilitar o controle da expansão urbana periférica e segregada ocorrido nas últimas décadas.

A política habitacional municipal não se mostra inclusiva e, atualmente, tem nos agentes privados a base para provisão e gestão da habitação social. O modelo de empreendimento contribui para a expansão e fragmentação urbana do território municipal, pois se vincula às localizações mais distantes do centro, junto à franja urbana, e a preços reduzidos.

Nesse sentido, pode-se afirmar que a atuação do Poder Público evidencia uma omissão em relação à pratica dos agentes privados e, consequentemente, a desarticulação entre a política urbana e a produção habitacional para a população de baixa renda.
O Poder Público, dessa forma, tem auxiliado no processo de segregação e desigualdade socioespacial pela omissão resultante de suas políticas urbanas e, principalmente, habitacionais.

Por fim, a análise dos empreendimentos residenciais financiados pelo PAR, em Presidente Prudente, possibilitou verificar a ausência de políticas públicas - urbana e habitacional - voltadas ao cumprimento da função social da cidade, reforçando o processo de produção do espaço urbano cada vez mais orientado pelos interesses do capital, que contribui para a expansão da malha urbana de forma segregada e fragmentada.

Conclui-se que a produção do espaço urbano neste município é produto direto do capital, sem interesse de controle ou direcionamento pelo Poder Público, fruto da ausência de uma política urbana socialmente justa e includente.

\section{REFERÊNCIAS}

ABREU, D. S. Poder Político Local no Populismo: Presidente Prudente (SP) 19281959. Presidente Prudente: Impress, 1996.

ALVIM, A. T. B.; CASTRO L. G. R.; ZIONI, S. Avaliação de políticas urbanas. In: ALVIM, A.T. B.; CASTRO, L.G.R. (orgs.). Avaliação de políticas urbanas - contexto e perspectivas. São Paulo: UPM/MackPesquisa/Romano Guerra Editora, 2010. p.13-41.

BONATES, M. F. O Programa de Arrendamento Residencial - PAR: acesso 
diferenciado à moradia e à cidade. Revista RISCO - PPG/DAU/EESC/USP, v.7. n.1,. p.147-164, 2008 Disponível em: $<w w w . a r q u i t e t u r a . e e s c . u s p . b r / r e v i s t a \_r i s c o /$ Risco7-pdf/02_art10_risco7.pdf>. Acesso em: 8 nov. 2008.

CAIXA ECONÔMICA FEDERAL. Cartilha do PAR - Módulo Arrendamento - jun. 2008. Disponível em: <www1.caixa.gov.br/gov/gov_social/estadual/ programas_habitacao/par/index.asp $>$. Acesso em: 08 dez. 2008.

CALDEIRA, T.P.R. Cidade de Muros: crime, segregação e cidadania em São Paulo. 2..ed. São Paulo: Ed.34/EDUSP. 2003.

CORRÊA, R.L. O Espaço Urbano. 4. ed. São Paulo: Ática, 1999.

CUNHA, E.P.; CUNHA, E.S.M. Políticas públicas sociais. In: CARVALHO et al. Políticas públicas. Belo Horizonte: UFMG/Proex, 2002. p.11-26.

FELDMAN, S. Política urbana e regional em cidades não-metropolitanas. In: GONÇALVES, M.F.; BRANDÃO, C.A.; GALVÃO, A.C.F. (orgs). Regiões e cidades, cidades nas regiões: $O$ desafio urbano-regional. São Paulo: UNESP/ANPUR, 2003, p. 105-112.

FERNANDES, S.A.S. Territorialização das políticas habitacionais em Bauru e Presidente Prudente - a atuação da CDHU, COHAB-CRHIS e COHAB-Bauru. 1998. $248 f$. Dissertação (Mestrado em Geografia). Faculdade de Ciências e Tecnologia, Universidade Estadual Paulista.

HONDA, S. C. A. L. A centralidade urbana em Presidente Prudente. 2000. 141f. Dissertação (Mestrado em Arquitetura e Urbanismo Faculdade de Arquitetura e Urbanismo, Universidade Presbiteriana Mackenzie.

HONDA, S. C. A. L. Habitação de Baixa Renda como Produto do Capital - o Programa de
Arrendamento Residencial (PAR) em Presidente Prudente. 2011. 204f. Tese (Doutorado em Arquitetura e Urbanismo). Faculdade de Arquitetura e Urbanismo, Universidade Presbiteriana Mackenzie.

LACAZE, J. P. A cidade e o urbanismo. Lisboa: Instituto Piaget/BBCC, 1999.

MARISCO, L. M O. Contribuição ao estudo do planejamento municipal no Brasil: o Plano Diretor de Desenvolvimento Integrado de Presidente Prudente (SP) 1969. 1997. 276f. Dissertação (Mestrado em Geografia). Faculdade de Ciências e Tecnologia, Universidade Estadual Paulista.

MARISCO, L. M. O. A norma e o fato: abordagem analítica da segregação sócioespacial e exclusão social a partir dos instrumentos urbanísticos. 2003. 212f. Tese (Doutorado em Geografia). Faculdade de Ciências e Tecnologia, Universidade Estadual Paulista.

MARQUES, E. A dinâmica imobiliária de incorporação em período recente. In: MARQUES, E.; TORRES, H. (org). São Paulo: Segregação, Pobreza e Desigualdades Sociais. São Paulo: Editora SENAC São Paulo, 2005. p.213-240.

MINISTÉRIO DAS CIDADES - GOVERNO FEDERAL DO BRASIL. SECRETARIA NACIONAL DE HABITAÇÃO. Política Nacional de Habitação. nov 2004. Disponível em: www.cidades.gov.br/secretarias-

nacionais/secretaria-de-habitacao/politicanacional-de-habitacao. Acesso em: 23 jun 2009.

MONTEIRO, J. V. Fundamentos da política pública. Rio de Janeiro: IPEA/INPES, 1982. ROLNIK et al. Plano Diretor Participativo guia para a elaboração pelos municípios e cidadãos. Brasília: CONFEA/Ministério das Cidades, 2004. Livro eletrônico: www.viaciclo.org.br/portal/documentos/doc _details/148-guia-elaboracao-plano-diretor- 
participativo-min-cidadesconfea. Acesso em: 01 nov 2008.

SANTOS, M. A urbanização brasileira. 5a..edição. São Paulo: EDUSP, 2005.

SEADE - Fundação Sistema Estadual de Análise de Dados - Grupos de Vulnerabilidade Social - Município de Presidente Prudente - 2000. Disponível em: www.seade.gov.br/produtos/ipvs/analises/pr esidenteprudente.pdf. Acesso em: 04 jun 2008.

SPOSITO. E. S. Produção e apropriação da renda fundiária urbana em Presidente Prudente. 1990. 230f. Tese (Doutorado em Geografia). Faculdade de Filosofia, Letras e Ciências Humanas, Universidade de São Paulo.

SPÓSITO, M. E. B. O 'chão' em Presidente Prudente: a lógica da expansão territorial urbana. 1983. 230f. Dissertação (Mestrado em Geografia). Instituto de Geociências e Ciências Exatas, Universidade Estadual Paulista.

TORREZAN, R. M. Reestruturação da cidade: localização de conjuntos habitacionais, estrutura e crescimento urbano em Presidente Prudente. 1992. 91f. Monografia (Graduação em Geografia). Faculdade de Ciências e Tecnologia, Universidade Estadual Paulista.

VALLADARES, L. P. (org.). Repensando a Habitação no Brasil. Rio de Janeiro: Zahar Editores, 1983.

VILLAÇA, F. Espaço Intra-Urbano no Brasil. São Paulo: Studio Nobel/FAPESP, 1998.

VILLAÇA, F. Uma contribuição para a história do planejamento urbano no Brasil. In: DÉAK, C; SCHIFFER, S.R (orgs). O Processo de Urbanização no Brasil. São Paulo, EDUSP, 1999, p.169-243.
Recebido para publicação em 10/08/2015 Revisado em 27/08/2015

Aceito em 01/09/2015 